\title{
Contribuição ao estudo anatômico da espécie Dialium guianense (Aubl.) Sandw. (Leguminosae)*
}

\author{
ARTHUR A. LOUREIRO \\ Instituto Nacional de Pesquisas \\ da Amazônia
}

\section{SINOPSE}

É apresentado o estudo macro e microscópico de Dialium guianense (Aubl.) Sandw., ocorrente em Manaus (Am.), cujos caracteres reportam-na como excelente madeira para fins comerciais.

\section{INTRODUÇÃo}

A finalidade precípua dêste trabalho consiste no estudo anatómico macro e microscopico, assim como $\mathrm{c}$ aspecto fotográfico do teciao lenhuso, as designações vulgares dos países que ocorre (no Brasil são relacionados os Estados e Territórios) e damos pequenos dados dendrológicos desta Leguminosae, com o objetivo de auxiliar a sua identificação taxonômica e ampliar o seu conhecimento, visto ser uma espécie de valor comercial e destacada por vários pesquisadores (Le Cointe, 1947; Ducke, 1949; Tavares, 1959; Fróes, 1959).

Dialium guianense (Aubl.) Sandw., é uma árvore que ocorre com freqüência nos Estados do Amazonas, Pará, Norte de Mato Grosso, Pernambuco, Bahia, Espirito Santo, Acre, Maranhão, Territórios Federais de Rondonia e Roraima, Guiana, América Central, na margem de certos rios e nas capoeiras de terra firme ou de várzea alta, de terreno arenoso e argiloso, sendo pouco freqüente na mata virgem. O seu porte é de mediano a alto. Segundo levantamento florestal realizado pelo INPA, na Estrada Manaus-Itacoatiara, a espécie atinge cêrca de 20 a 30 metros de altura, com um diâmetro médio até $50 \mathrm{~cm}$.

O tronco da árvore apresenta pequenas sapopemas na base, o fuste é ereto e cilíndrico, casca lisa, fina, exudando seiva viscosa, vermeIho sangue. Os frutos são pequenos, globosos, agridoces, comestiveis.

\section{MATERIAL E MÉTODOS}

Os corpos de provas foram retirados da parte mais externa do lenho. O método empregado na preparação das lâminas para o estudo anatômico foi o comumente usado em Xilologia. As lâminas estão registradas e arquivadas no laminário do INPA.

A madeira em estudo encontra-se registrada na Xiloteca do INPA, acompanhada do material botânico. A terminologia usada para a descrição anatômica segue o "Glossário de têrmos técnicos usados em anatomia de madeiras" (Milanez \& Bastos, 1960).

\section{OCORRÊNCIAS E DESIGNAÇÕES VULGARES}

BRASIL

Estado do Amazonas: Jutaícica, jutaí; j. pororoca, pororoca (Ducke, 1949; Fróes, 1959).

Estado do Acre: Jutaí pororoca (Herbábário do INPA, 18.349).

Estado do Pará: Pororoca, jutaí, jutaípeba, parajuba, j. mirim, cururu, Itu (Le Cointe, 1947).

Estado do Maranhão: Sucupembinha (Herbário do INPA, 20.842).

Estado de Pernambuco: Pau-ferro (Tavares, S. 1959).

Estado de Espírito Santo: Quebra machado, durinho (Milanez \& Mattos Filho, 1956).

Território Federal de Rondônia: Jutaí (Herbário INPA, 22.093).

Território Federal de Roraima: Jutaí pororoca (Herbário do INPA, .... 19.006).

(*) - Trabalho executado com auxílio do Conselho Nacional de Pesquisas. 
MÉxICO - Guapigue, paque, wapak, (Record \& Ress, 1949).

G. HOLANDESA - Ironwood, uhee-tee. (ibid.). AMćrica Central - Tamarino (ibid.).

HONDURAS - Tamarino prieto, paleta (ibid.) .

NICARÁGUA - Comenegro, slim, tamarindo montero (ibid.)

guatemala - Paleta (ibid.) .

PANAMÁ - Fria, monkey, tamarindo de montaña (ibid.).

COLÔMBIA - Granadillo (ibid.).

venezuela - Cacho (ibid.).

PERU - Huitillo (ibid.).

\section{DADOS GERAIS SOBRE A MADEIRA}

\section{CARACTERÍSTICAS GERAIS}

Madeira muito pesada (pêso específico de 0,95 a $1,10 \mathrm{~g} / \mathrm{cm}^{3}$ ): cerne apresentando um castanho avermelhado sujo, bem diferenciado do alburno creme, grã regular; textura média para grosseira; superfície pouco lisa ao tato de briIho levemente acentuado, insípida e inodora. Relativamente difícil de trabalhar em virtude da grarıde quantidade de massas de sílica, exclusivamente no perênquima. Encontrando-se também no lenho oxalato de cálcic em pequena proporção (Milanez \& Mattos, 1956). Recebe bom acabamento com polimento pouco atrativo.

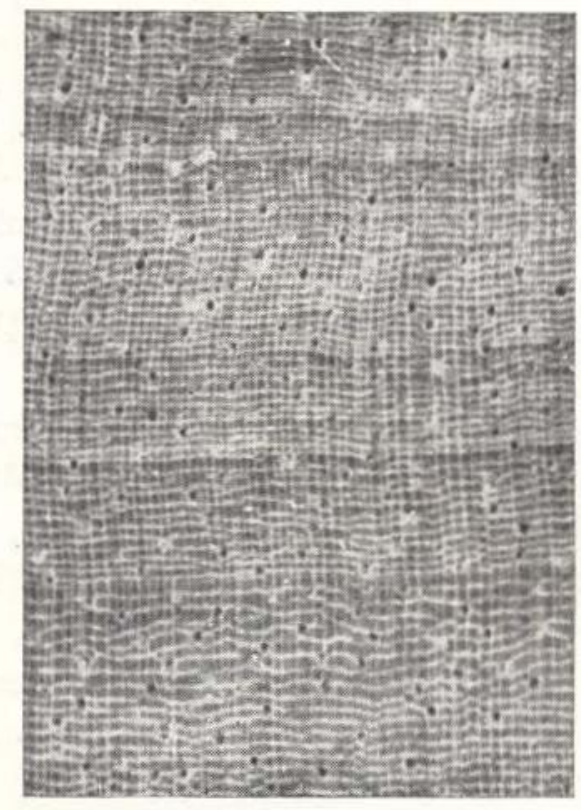

Fig. 1 - Secção transversal (10x)

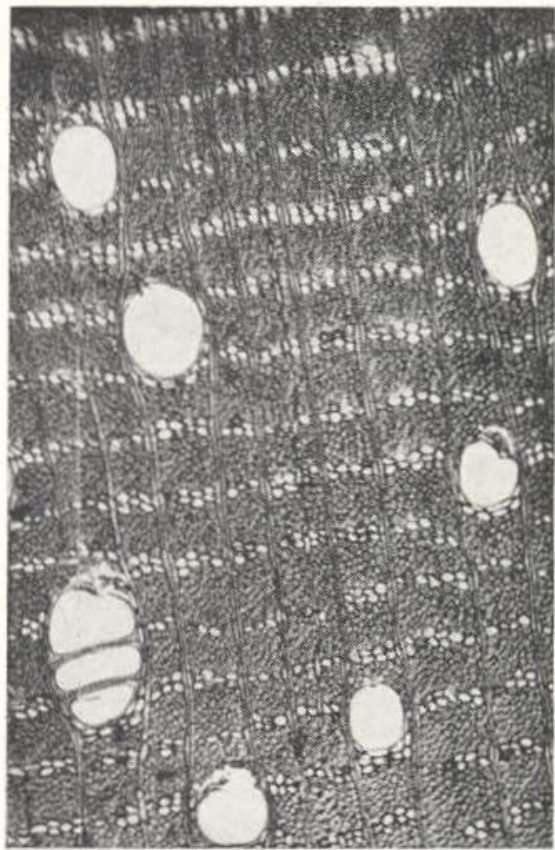

Fig. 2 - Secção transversal $(60 x)$

\section{DESCRIÇÃO MACROSCÓPICA}

Parênquima relativamente abundante, distinto sob lente em finas linhas regulares, aproximadas, às vêzes interrompidas, pouco sinuosas tangenciando os poros, formando um retículo com os raios, às vêzes associadas, aparentemente formando pequenas faixas apenas visiveis a ôlho desarmado. Poros abundantes visíveis só com ajuda de lente, solitários predominantes, múltiplos de $2 \cdot 3$, às vêzes de 4 poros, vazios, de pouco numerosos a numerosos, pequenos, alguns médios. Linhas vasculares bem visíveis sem auxilio de lente, retas, longas, profundas, contendo resina. Raios no tôpo são finos e numerosos, apresentando boa uniformidade na largura e espaçamento; na face tangencial a sua estratificação $(4$ por $\mathrm{mm}$ ) apenás visiveis a ôlho nu, uniforme; na face radial notaáos a simples vista. Camadas de crescimento bem distintas sem auxílio de lente, demarcadas por zonas fibrosas mais escuras. Maculas medulares e canais secretores não foram observados.

DESCRIÇÃO MICROSCÓPICA :

Vasos de distribuição diflisa, secção circular, espessura da parede média, diâmetro tangencial de 98-175 micra, pequenos a médios. 


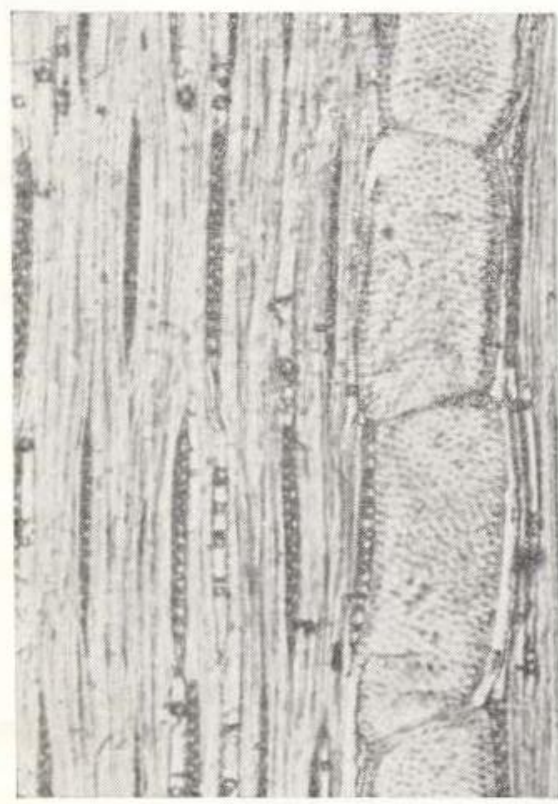

Fig. 3 - Secção transversal $(70 x)$

de poucos a poucos numerosos, variando de 4- 12 vasos por $\mathrm{mm}^{2}$, predominantemente soli. tários $(62 \%)$, múltiplos de $2 \cdot 3-4$, acentuada predominância dos geminados $(35 \%)$, pontuações intervasculares em disposição alterna, guarnecidas, médias 6 - 7 micra, abertura inclusa com placas de perfurações simples; elementos vasculares de 270 - 395 micra de comprimento. Raios apresentando estratificação bem distribuída e uniforme de 4 por milímetro, homocelulares (Kribs II), unisseriados com predominância dos trisseriados, extremamente baixos de 200-300 micra de comprimento, com 10-19 células de altura, numerosos 7 - 10 por milímetro, pontuações radiovasculares do mesmo tipo das intervasculares. Parênquima apotraqueal de 1 - 3 células, encontrando-se também em pe. quena quantidade oxalato de cálcio. Fibras com parede grossa, pontuações simples, de lúmen reduzido. Elementos fibrosos de curtos a longos, variando de 1.320 - 1.980 micra de comprimento. Camadas de crescimento distintas, ocasionalmente demarcadas por zonas fibrosas. Estratificação é encontrada em todos os elementos. Máculas medulares e canais intercelulares não foram observados.

\section{Usos comuns:}

Construção civil, obras hidráulicas, dormentes, vigamentos, esteios, estacas de cêrca, ótima para peças de resistência.

Material consultado :

Madeira INPA X-796 (Herbário 8213); Mad. INPA X-2025 (Herbário 14.241); Mad. INPA X-3638 (Herbário 17.365); Mad. INPA X-3700 (Herbário 17.364); Mad. INPA X-1725; Mad. INPA X-4123 (Herbário 28, 186); IAN n. 3530.

\section{SUMMARY}

In this paper the author gives macroscopic and microscopic characters of the following species of Leguminosae: Dialium guianense (Aubl.) Sandw. 3 illustrations of anatomical struture of the woods described and some dendrological data are presentec'.

\section{BIBLIOGRAFIA CITADh}

DUCKE, A .

1949 - Notas sôbre a flora neotrópica. II - As leguminosas da Amazônia brasileira. 2. ed. Bol. Téc. Inst, Agr. Norte, Belém, 18: 112.

FróEs, R. L.

1959 - Informações sôbre algumas plantas econômicas do Planalto Amazônico. Bol. Téc. Inst. Agr. Norte, Belém, 35 : 59

Le Colnte, P.

1947 - Amazônia brasileira. III - Arvores e plantas úteis (indigenas $e$ aclimadas). 2. ed. Sâo Paulo, Ed. nac. p. 409, 14 est. (Brasiliana, série : 5 , v. 251)

Milanez, F. R. \& Bastos, A. De Miranda

1960 - Glossário dos têrmos usados em anatomia de madeiras. An. bras, econ. flor., Rio de Janeiro, 12(12): 1-27.

Milanez, F, R. \& Mattos, F. A. DE

1956/57 - Nota sôbre a ocorrência de silica no lenho de Leguminosas. Rodriguesia, $38 / 39$ (30-31).: 7-11.

RECORD, S. J. \& RESS, W.

1949 - Timbers of the New World. 4. ed. New Haven, Yale Univ. Press. p. 259.

TAVARES, S

1959 - Madeiras do Nordeste do Brasil. Recife, Univ. rur. de Pernambuco, p. 65 (Monografia, 5). 